\title{
Efeitos do sombreamento na anatomia foliar de Gallesia integrifolia (Spreng) Harms e Schinnus terebinthifolius Raddi
}

SANTOS, M.S. ${ }^{1}$; FEIJÓ, N.S.A. ${ }^{1}$; SECCO, T.M. ${ }^{1}$; MIELKE, M.S. ${ }^{1}$; GOMES, F.P. ${ }^{1}$; COSTA, L.C.B. ${ }^{1}$; SILVA, D.C. ${ }^{1 *}$ ${ }^{1}$ Universidade Estadual de Santa Cruz. Campus Soane Nazaré de Andrade. Rodovia Ilhéus-Itabuna, Km 16, CEP: 45662-900, Ilhéus-Brasil. delmira@uesc.br

\begin{abstract}
RESUMO: Realizou-se estudo com o objetivo de analisar as alterações na anatomia foliar de Gallesia integrifolia (Spreng) Harms e Schinnus terebinthifolius Raddi quando cultivadas em ambientes de sombra moderada ou densa, simulando as condições naturais encontradas em sistemas agroflorestais tradicionais do sul da Bahia, Brasil. Plantas das duas espécies, com aproximadamente um ano de idade, foram cultivadas em casa de vegetação sob quatro níveis de sombreamento $(25 \%, 17 \%, 10 \%$ e $5 \%)$. Estudos anatômicos do limbo foliar foram realizados a partir de material incluído em parafina e seccionado em micrótomo rotativo. Os diferentes níveis de sombreamento ocasionaram alterações na estrutura do mesofilo de ambas as espécies, com diferenças significativas na espessura do parênquima paliçádico, limbo foliar, e densidade estomática. Nas condições em que o experimento foi realizado os resultados obtidos indicaram que $G$. integrifolia apresenta maior capacidade de aclimatação a ambientes de sombra moderada e densa do que $S$. terebinthifolius, sendo mais indicada para o cultivo em sistemas agroflorestais pré-estabelecidos.
\end{abstract}

Palavras chaves: Gallesia integrifolia, Schinnus terebinthifolius, anatomia foliar, sistemas agroflorestais.

\begin{abstract}
Effects of shading on leaf anatomy of Gallesia integrifolia (Spreng) Harms and Schinnus terebinthifolius Raddi. This study was conducted with the aim of analyzing the changes in the leaf anatomy of Gallesia integrifolia (Spreng) Harms and Schinnus terebinthifolius Raddi when grown in environments with moderate to dense shade, simulating the natural conditions found in traditional agroforestry systems in southern Bahia, Brazil. Plants of both species, being approximately one year-old, were grown at four irradiance levels $(25 \%, 17 \%$, $10 \%$ and $5 \%$ ) in a greenhouse. Leaf anatomical studies were made from material embedded in paraffin and sectioned on a rotary microtome. The different irradiance levels caused a shift in the mesophyll anatomy of both species, with significant differences in palisade parenchyma thickness and leaf stomatal density. In the conditions of this experiment, the results indicated that $G$. integrifolia has a higher capacity for acclimatization to moderate to dense shade than $S$. terebinthifolius, and it is thus more suitable for cultivation in pre-established agroforestry systems.
\end{abstract}

Keywords: Gallesia integrifolia, Schinnus terebinthifolius, leaf anatomy, agroforestry systems.

\section{INTRODUÇÃO}

Nas regiões tropicais, o uso de espécies arbóreas nativas com valor comercial tem sido indicado como importante alternativa econômica para a implementação e viabilidade de sistemas agroflorestais (Rao et al., 2004). Além disso, no caso de sistemas agroflorestais pré-estabelecidos, a inclusão de espécies arbóreas não-madeireiras pode ser uma estratégia para agregar valor ao sistema produtivo, ampliando a biodiversidade local e diminuindo os riscos causados pelas oscilações do mercado (Ticktin \& Shackleton, 2011). Assim, o desenvolvimento de estudos sobre os efeitos dos fatores físicos do ambiente no crescimento e no desenvolvimento dessas espécies é de grande importância para a definição de estratégias de plantio voltadas para cultivos consorciados, ou para a sua introdução em sistemas pré-estabelecidos (Feijó et al., 2008).

No sudeste da Bahia os sistemas agroflorestais tradicionais têm como base o cultivo 
do cacaueiro (Theobroma cacao L.) no sub-bosque de remanescentes de florestas naturais raleadas. Apesar de sua importância cultural e para a conservação da água, do solo, e da biodiversidade local, o cultivo tradicional do cacaueiro vem sofrendo uma séria crise, ocasionada pelas oscilações de preços no mercado internacional e pela epidemia conhecida como vassoura-de-bruxa (doença causada pelo fungo Moniliphthora perniciosa (Stahel) Aime e Phillips-Mora (Cassano et al., 2009). Nesse sentido, a reintrodução de espécies nativas não-madeireiras nas áreas sob cultivo pode auxiliar na manutenção da biodiversidade local e, ao mesmo tempo, agregar valor aos sistemas agroflorestais já estabelecidos. Por outro lado, esses sistemas tradicionais são muito heterogêneos em relação às espécies, ao tipo de manejo e a densidade de árvores (Schroth et al., 2011); tornando-se necessário o desenvolvimento de estudos sobre o comportamento das plantas que serão introduzidas em diferentes ambientes de luz. Além disso, independentemente do manejo utilizado, a sombra ocasionada pelos cacaueiros pode ser considerada como densa ou muito densa.

Entre os principais fatores físicos do ambiente que afetam o crescimento e o desenvolvimento vegetal destacam-se a disponibilidade da radiação luminosa, água, temperatura, e nutrientes (Lambers et al., 2008). Em ambientes florestais, a grande variação na disponibilidade da radiação incidente pode ser um fator limitante ao crescimento de plântulas e indivíduos jovens de determinadas espécies (Valladares \& Niinemets, 2008). A folha é o principal órgão fotossintetizante, geralmente apresentando grande plasticidade fenotípica em relação à radiação luminosa (Valladares \& Niinemets, 2008; Sanches et al., 2009), cuja disponibilidade e a qualidade podem provocar efeitos substanciais no desenvolvimento, tamanho e espessura desse órgão (Hanba et al., 2002; Aranda et al., 2004). Quando se desenvolvem a pleno sol as folhas são, geralmente, mais espessas e têm maior capacidade fotossintética por unidade de área, devido ao incremento da quantidade de enzimas e maior condutância estomática, que folhas sombreadas (Valladares \& Niinemets, 2008). Entretanto, o potencial de aclimatação à luz é variável entre as espécies, algumas podem aumentar sua capacidade fotossintética quando transferidas de baixa para alta irradiancia, ou não, podendo este padrão variar de acordo com a plasticidade anatômica (Oguchi et al., 2003, 2005). Dessa forma, avaliações anatômicas das respostas das plantas aos diferentes níveis de sombreamento são de grande importância para o desenvolvimento de sistemas de manejo visando o aproveitamento de espécies arbóreas em sistemas agroflorestais.
Gallesia integrifolia é uma espécie arbórea conhecida popularmente como pau-d'alho, pelo forte cheiro de alho emitido por sua casca, a qual é utilizada na medicina popular para preparação de chás, no tratamento de gripe, tosse, pneumonia, verminoses, gonorréia, tumores de próstata e reumatismo (Lorenzi, 2002). Trata-se de uma espécie com ampla ocorrência na Mata Atlântica, desde o nordeste ao sudeste e no Brasil Central, em florestas secundárias, mata ciliar e nas áreas cultivadas com cacaueiro no sul da Bahia (Sambuichi, 2009). Por outro lado, Schinnus terebinthifolius é uma espécie pioneira, conhecida popularmente como aroeiravermelha, aroeira-pimenteira ou aroeirinha. $\mathrm{Na}$ medicina popular é utilizada por suas propriedades antiinflamatória, cicatrizante e antimicrobiana contra fungos e bactérias (Guerra et al., 2000; Lucena et al., 2006) e comercialmente pelo consumo de seu fruto, a "pimenta-rosa", na cozinha nacional e internacional, como condimento alimentar e, ainda, como planta ornamental. No Brasil, tem distribuição desde o estado de Pernambuco até o Rio Grande do Sul, sendo encontrada em várias formações vegetais, desde florestas ombrófilas em formação secundária até matas ciliares, restingas e áreas cultivadas com cacaueiros (Sambuichi, 2009).

A escassez de conhecimentos sobre alterações foliares decorrentes da exposição de espécies arbóreas da Mata Atlântica a diferentes níveis de sombreamento, como estratégia de apoio na seleção de espécies nativas para o enriquecimento de sistemas agroflorestais, motivou o desenvolvimento deste estudo. Assim, o objetivo desse trabalho foi analisar as alterações na anatomia foliar de G. integrifolia e S. terebinthifolius, cultivadas em ambientes de sombra moderada ou densa, simulando as condições naturais encontradas em sistemas agroflorestais tradicionais do sul da Bahia.

\section{MATERIAIS E MÉTODOS}

$O$ experimento foi realizado em casa de vegetação e os estudos anatômicos no Laboratório de Anatomia Vegetal da Universidade Estadual de Santa Cruz (UESC), Ilhéus, BA. Mudas de G. integrifolia e $S$. terebinthifolius provenientes do Instituto Biofábrica de Cacau (IBC), Ilhéus, BA, foram utilizadas com aproximadamente quatro $\mathrm{e}$ cinco meses de idade, respectivamente. Um total de 40 plantas de tamanho uniforme por espécie foi selecionado, as quais foram transplantadas para baldes plásticos, contendo $10 \mathrm{~kg}$ de solo de mata. Metade das plantas, 20 indivíduos, foi cultivada nas condições naturais da casa de vegetação e a outra parte, de igual quantidade, distribuída em três ambientes de sombra. $O$ sombreamento foi obtido por meio de estruturas

Rev. Bras. PI. Med., Campinas, v.16, n.1, p.89-96, 2014. 
com cobertura total de tela preta $(25,50$ e $75 \%$ de atenuação da radiação solar), com dimensões de 3,0 $\times 1,5 \times 1,0 \mathrm{~m}$. Durante o experimento, a radiação fotossinteticamente ativa (RFA) de cada ambiente de sombra e na casa de vegetação foi monitorada por meio de sensores de radiação luminosa S-LIA-M003, acoplados a uma estação climatológica Hobo Micro Station Data Logger (Onset, USA). A média dos valores diários totais de RFA variou entre 6,$0 ; 4,0 ; 2,3$ e $1,1 \mathrm{~mol} \mathrm{~m}^{-2}$ $\mathrm{dia}^{-1}$, na casa de vegetação e nas estruturas de sombreamento com $25 \%, 50 \%$ e $75 \%$ de atenuação da radiação solar, respectivamente (Feijó et al., 2008). Tais valores corresponderam, respectivamente, a $17 \%, 10 \%$ e $5 \%$ da radiação solar disponível em relação ao pleno sol.

Após quatro meses de cultivo foram realizadas coletas para as análises anatômicas. A espécie $S$. terebinthifolius, que possui folhas compostas, foram utilizadas três repetições (folhas) de cada tratamento, e para cada repetição foram coletados três folíolos. Enquanto que para G. integrifolia, que possui folhas simples, foram coletadas três repetições para cada tratamento. As folhas de ambas as espécies foram coletadas maduras e completamente expandidas, ou seja, entre a segunda e a quarta folhas a partir do ápice dos ramos. Amostras da folha foram fixadas em FAA $70 \%$ (formalina, ácido acético, álcool etílico $70 \% ; 1: 1: 18 \mathrm{v} / \mathrm{v}$, Johansen 1940) com auxilio de bomba de vácuo e conservadas em álcool etílico $70 \%$. As porções da região mediana da folha foram desidratadas em série etílica butílica, incluídas em parafina (Johansen 1940), seccionadas em micrótomo rotativo Leica @ modelo RM 2145 a $5 \mu \mathrm{m}$ de espessura e coradas com safranina e azul de astra (Gerlarch, 1969), montadas em bálsamo do Canadá.

As observações e documentação foram feitas utilizando o microscópio fotônico Olympus BX-50. As imagens foram digitalizadas e analisadas com auxílio do software Sigma Scan. Nestas análises foram efetuadas medições em 10 campos distintos de cada amostra. Foram mensurados a espessura da epiderme nas faces adaxial e abaxial; do parênquima paliçádico e esponjoso; espessura do mesofilo; o número de camadas de células do parênquima paliçádico e esponjoso e a área dos espaços intercelulares. $\mathrm{Na}$ análise da densidade estomática foi adotado o método da réplica, utilizando-se uma amostra de cada repetição, e a média da contagem em cinco campos distintos de cada amostra.

Todas as variáveis quantificadas foram submetidas à análise de variância e a comparação das médias foi feita pelo teste de Tukey a $5 \%$ de probabilidade.

\section{RESULTADOS E DISCUSSÃO}

A Figura 1 apresenta o curso diurno da RFA no interior da casa de vegetação e nos ambientes de sombreamento durante quatro dias não-consecutivos entre julho e agosto de 2006. No pleno sol a RFA máxima chegou a valores próximos de $2000 \mu \mathrm{mol}$ fótons $\mathrm{m}^{-2} \mathrm{~s}^{-1}$, sendo a média dos valores máximos em torno de $1200 \mu \mathrm{mol}$ fótons $\mathrm{m}^{-2} \mathrm{~s}^{-1}$ (Figura 1A). Nos tratamentos $25 \%$ e $17 \%$ do pleno sol a RFA máxima atingiu valores médios em torno de $350 \mu \mathrm{mol}$ fótons $\mathrm{m}^{-2} \mathrm{~s}^{-1}$, ao passo que no tratamento $10 \%$ do pleno sol tais valores raramente chegaram a $150 \mu \mathrm{mol}$ fótons $\mathrm{m}^{-2} \mathrm{~s}^{-1} \mathrm{e}$ no tratamento $5 \%$ do pleno sol esses valores estiveram sempre abaixo de $100 \mu \mathrm{mol}$ fótons $\mathrm{m}^{-2} \mathrm{~s}^{-1}$ (Figura 1B). Tais resultados demonstram que as plantas estavam sob condições de sombra moderada ou densa, similar aos resultados previamente relatados para sistemas agroflorestais tradicionais do sul da Bahia (Miyaji et al., 1997).

Os tratamentos de sombreamento afetaram as características anatômicas das folhas $G$. integrifolia e S. terebinthifolius. A espessura do limbo,
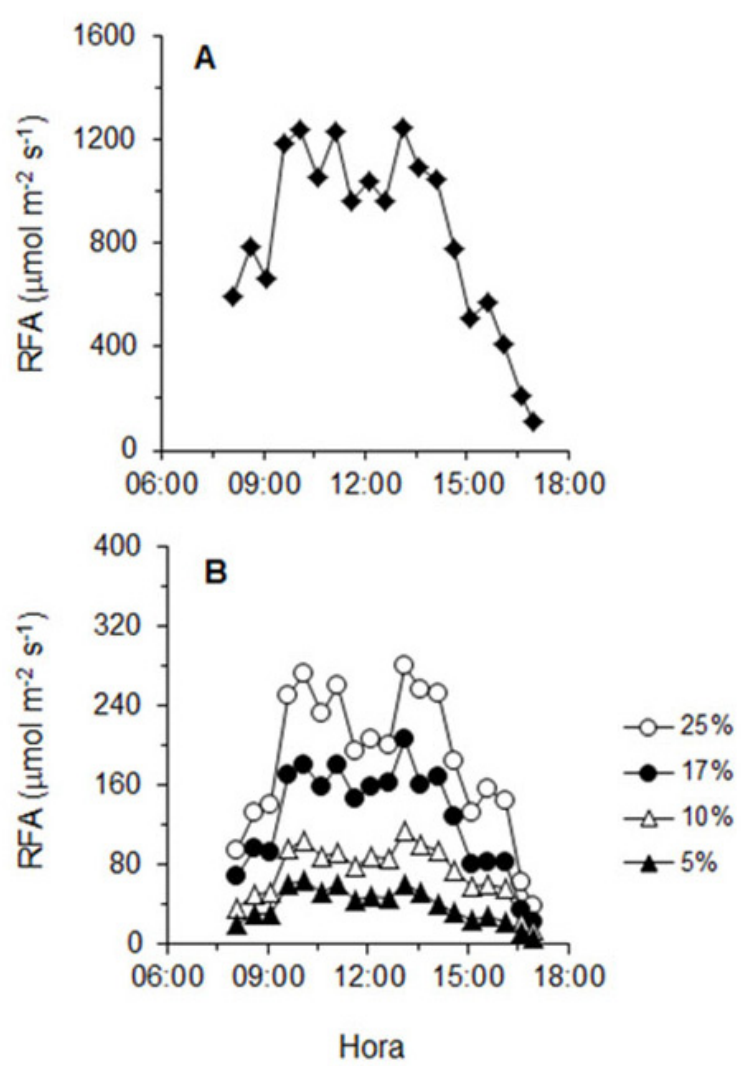

FIGURA 1. Curso diurno da radiação fotossinteticamente ativa (RFA) no pleno sol (A) e nos quatro ambientes de cultivo (B). Os valores correspondem a médias de quatro dias nãoconsecutivos entre julho e agosto de 2006. 
do mesofilo foliar e do parênquima paliçádico foram os que mais diferiram entre os quatro tratamentos, com valores médios mais elevados para plantas cultivadas sob $17 \%$ do pleno sol (Tabelas 1 e 2 ). Nesse ajuste estrutural a variação da espessura da lâmina foliar, ao longo do gradiente de luz representa uma estratégia para maximizar a capacidade fotossintética desse órgão (Poorter, 1999).

$\mathrm{Na}$ epiderme uniestratificada, formada por células de formato retangular em $S$. terebinthifolius e cúbico a retangular em G. integrifolia (Figura 2 ), notou-se que a face adaxial, para ambas as espécies, não apresentou diferença significativa quando comparadas ao tratamento de $25 \%$ do pleno sol. Essa diferença também não foi observada na face abaxial de $S$. terebinthifolius. Já na face abaxial de G. integrifolia, houve diferença significativa no tratamento de $17 \%$ em relação ao $25 \%$ de atenuação solar (Tabela 1).

Em G. integrifolia um aspecto que chamou atenção foi ocorrência de hipoderme apenas nos tratamento de $25 \%$ e $17 \%$ da atenuação solar (Tabela 1 e Figura 1A-D). A potencialidade plástica da hipoderme, como resposta à variação da intensidade luminosa tem sido reportada em espécies como Tradescantia pallida, onde Paiva et al. (2003) observaram que a hipoderme que ocupava mais de $50 \%$ da espessura da folha apresentou redução do tamanho de suas células e número de camadas, proporcional à redução da intensidade de luz. Já em Metrosideros polymorpha, esta capacidade de ajuste estrutural foi considerada por Cordel et al. (1998) como um dos principais fatores envolvidos na grande variação fenotípica e dominância vegetacional dessa espécie, com ampla distribuição ao longo de vários habitats.

A camada hipodérmica, característica da folha G. integrifólia (Akisue et al. 1986), se tornou ausente nos tratamentos de maior sombreamento demonstra a capacidade de ajuste estrutural face à baixa disponibilidade de luz, evidenciado assim, sob o ponto de vista ecológico, o grau de plasticidade fenotípica dessa espécie. Segundo Dickison (2000) o modelo clássico de resposta e adaptação à alta intensidade luminosa é o aumento da espessura da folha, da epiderme e do parênquima paliçádico, bem como do número total de células das folhas.

Os estômatos restritos à face abaxial caracterizam a folha de ambas as espécies como hipoestomática, aspecto considerado como uma estratégia fotoprotetora a alta intensidade luminosa (Dickison, 2000). O aumento na densidade estomática é importante, pois permite que a planta eleve a condutância de gases evitando assim que a fotossíntese seja limitada sob condições ambientais adversas (Lima Jr. et al., 2005). Em G. integrifolia a baixa disponibilidade de radiação luminosa acarretou um acréscimo na densidade estomática,

TABELA 1. Espessura $(\mu \mathrm{m})$ do limbo e dos componentes anatômicos foliares de $G$. integrifolia e $S$. terebinthifolius em diferentes níveis de sombreamento $A D$, espessura da epiderme face adaxial; $A B$, espessura da epiderme face abaxial; HP, espessura da hipoderme; PP, espessura do parênquima paliçádico; $P E$, espessura do parênquima esponjoso; MF, espessura do mesofilo; LF, espessura do limbo foliar; DE, densidade estomática ( $\mathrm{mm}^{2}$ ); e El, área dos espaços intercelulares $\left(\mu \mathrm{m}^{2}\right)$.

\begin{tabular}{|c|c|c|c|c|c|}
\hline \multirow[b]{2}{*}{ Espécie } & \multirow[b]{2}{*}{ Componentes } & \multicolumn{4}{|c|}{$\%$ do pleno sol } \\
\hline & & 25 & 17 & 10 & 5 \\
\hline \multirow[t]{9}{*}{ G. integrifolia } & $A D$ & $24,7 \pm 5,7 a$ & $27,0 \pm 5,0 a$ & $26,8 \pm 4,0 a$ & $26,5 \pm 4,1 a$ \\
\hline & $A B$ & $27,8 \pm 3,5 a$ & $22,1 \pm 4,7 b$ & $22,4 \pm 4,5 a$ & $23,3 \pm 4,4 a b$ \\
\hline & HP & $32,7 \pm 4,0 a$ & $18,3 \pm 6,0 a b$ & - & - \\
\hline & PP & $60,6 \pm 12,0 a$ & $57,2 \pm 11,2 a b$ & $39,0 \pm 5,7 b c$ & $33,3 \pm 5,6 c$ \\
\hline & PE & $115,3 \pm 25,3 a$ & $119,3 \pm 33,6 a$ & $84,2 \pm 13,8 a$ & $93,8 \pm 21,3 a$ \\
\hline & MF & $208,6 \pm 23,9 a$ & $194,8 \pm 29,4 a$ & $123,2 \pm 11,9 b$ & $127,2 \pm 17,9 b$ \\
\hline & LF & $261,0 \pm 25,3 a$ & $243,8 \pm 33,6 a b$ & $172,5 \pm 13,8 a b$ & $177,1 \pm 21,3 a b$ \\
\hline & DE & $15,0 \pm 1,6 b$ & $15,0 \pm 1,2 b$ & $17,0 \pm 2,2 b$ & $23,0 \pm 2,1 \mathrm{a}$ \\
\hline & El & $20,5, \pm 2,4 b$ & $30,6 \pm 3,1 a$ & $34,2 \pm 6,6 a$ & $36,2 \pm 5,0 a$ \\
\hline \multirow[t]{9}{*}{ S. terebinthifolius } & $A D$ & $31,10 a$ & $29,8 \pm 6,2 a$ & $26,3 \pm 4,0 a$ & $27,0 \pm 5,8 a$ \\
\hline & $A B$ & $26,1 \pm 5,5 a$ & $26,8 \pm 6,2 a$ & $26,0 \pm 4,6 a$ & $23,2 \pm 4,9 a$ \\
\hline & HP & - & - & - & - \\
\hline & PP & $213,0 \pm 15,3 a$ & $125,2 \pm 25,6 a b$ & $137,8 \pm 28,3 b$ & $108,0 \pm 23,0 c$ \\
\hline & PE & $132,1 \pm 37,4 a$ & $143,0 \pm 14,0 a$ & $137,1 \pm 15,4 a$ & $132,1 \pm 26,8 a$ \\
\hline & MF & $345,1 \pm 37,5 a$ & $268,0 \pm 28,2 a$ & $274,9 \pm 29,9 b$ & $247,4 \pm 3,9 b$ \\
\hline & LF & $402,3 \pm 38,7 a$ & $324,7 \pm 30,3 b$ & $327,2 \pm 30,8 b$ & $297,6 \pm 40,0 b$ \\
\hline & DE & $52,0 \pm 6,6 a$ & $52,0 \pm 8,6 a$ & $53,0 \pm 6,5 a$ & $54,0 \pm 10,2 a$ \\
\hline & $\mathrm{El}$ & $21,3 \pm 3,0 a$ & $29,6 \pm 3,7 a$ & $24,5 \pm 1,8 a$ & $26,4 \pm 3,5 a$ \\
\hline
\end{tabular}

Médias seguidas de mesma letra na coluna não diferem entre si pelo teste de Tukey em nível de $5 \%$ de probabilidade.

Rev. Bras. PI. Med., Campinas, v.16, n.1, p.89-96, 2014. 
com diferença significativa entre o tratamento $5 \%$ quando comparado ao de $25 \%$ do pleno sol (Tabela 1). Esses resultados estão de acordo com os obtidos para outras espécies, nas quais ocorreu aumento na densidade estomática nos níveis mais elevados de sombreamento (Lima Jr. et al., 2006; Morais et al., 2004). Enquanto, para S. terebinthifolius não foi observada diferenças significativas entre os tratamentos (Tabela 1).

O mesofilo do tipo dorsiventral foi característico nas duas espécies, com número constante de camadas do parênquima paliçádico e esponjoso em todos os tratamentos (Figura 2). Nas espécies analisadas, a espessura do mesofilo e do limbo foliar apresentou diferenças significativas nos tratamentos quando comparado ao $25 \%$ do pleno sol (Tabela 1). Esta redução na espessura está relacionada com o menor espessamento das células do parênquima paliçádico. No entanto, em G. integrifolia verificou-se que a redução ocorreu, também, como consequência do desaparecimento da camada hipodérmica a partir do tratamento com 10\% (Figura 2). Em geral, folhas de sombra apresentam redução na espessura do mesofilo e aumento da área do limbo foliar (Santiago et al., 2001; Lima Jr. et al., 2006; Castro et al., 2007; Gomes et al., 2008; Gondim et al., 2008), para obterem uma maior superfície de absorção e otimização da captura de fótons (Gorton et al., 1999).

Durante a passagem da radiação através da folha, esta atravessa sucessivas camadas de células, ocasionando o declínio de sua intensidade
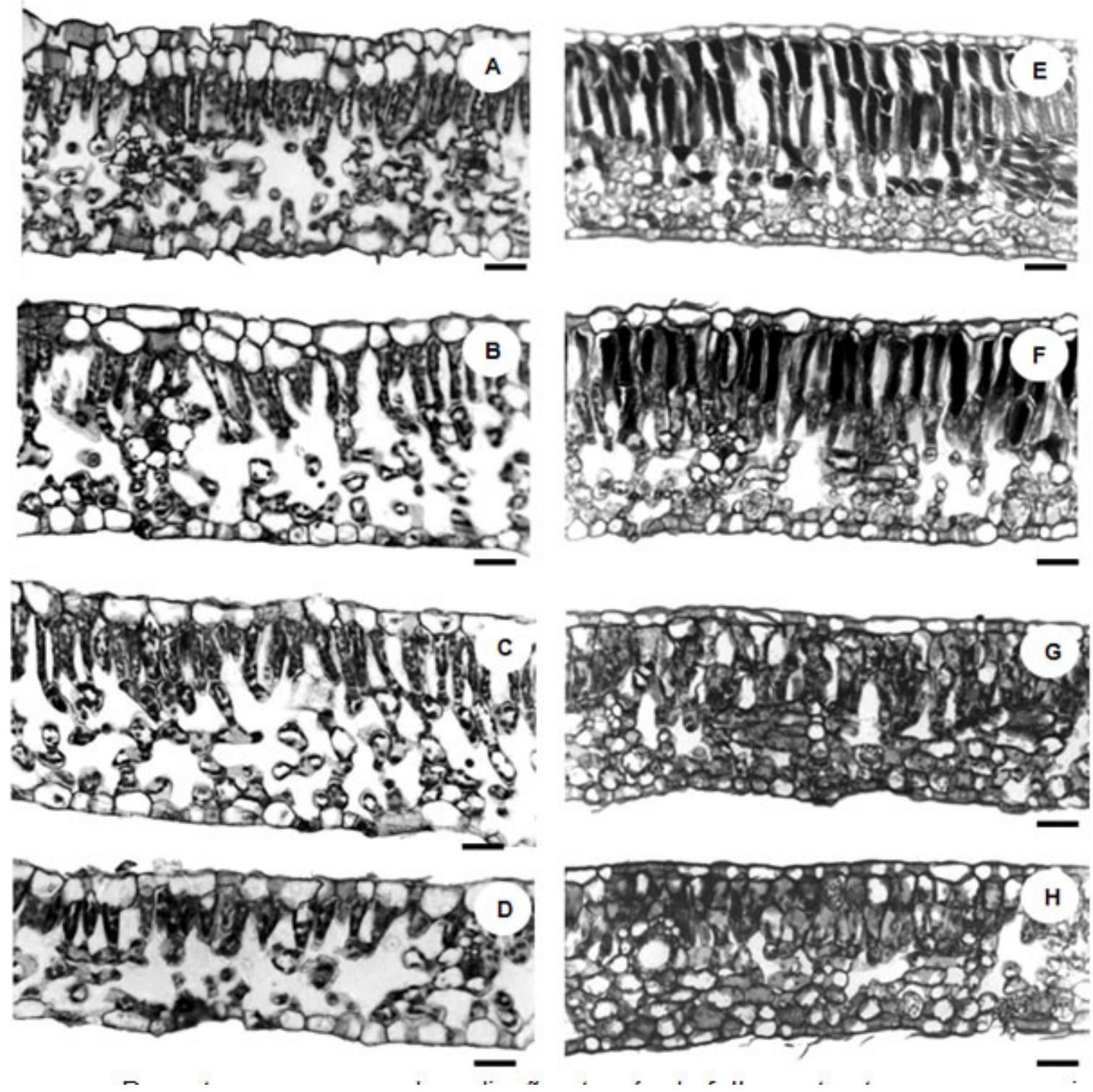

FIGURA 2. Seção transversal da folha de G. integrifolia (A, B, C e D) e S. terebinthifolius (E,F,G e H) submetida a diferentes níveis de sombreamento: pleno sol ( $A$ e E) ; 17\% (B e F);10\% (C e G) e 5\% (D e H). C e F. Barra $=10 \mu \mathrm{m}$. 
(Niinemets \& Sack et al., 2006). Nas duas espécies ocorreu uma alteração significativa apenas da espessura do parênquima paliçádico, o qual sofreu redução com o aumento do sombreamento (Tabela 1 ), especialmente em $G$. integrifolia, onde as células deste tecido apresentaram-se mais curtas, com formato irregular e arranjadas frouxamente formando amplos espaços intercelulares (Figura 2 A-D). Foi observado ainda, que nas células deste tecido os cloroplastos assumiram uma posição voltada para os espaços intercelulares, posicionados perpendicularmente à penetração da radiação luminosa na superfície foliar. Resultados semelhantes foram observados por Brant et al. (2011) ao avaliarem a espessura do parênquima paliçádico e lacunoso, bem como a disposição dos cloroplastos nos tecidos foliares de Melissa officinalis submetida ao pleno sol e a $60 \%$ de intensidade luminosa.

Diversos estudos têm constatado que folhas de sol apresentam maior desempenho sob alta luminosidade, enquanto que folhas de sombra têm melhor desempenho sob baixa luminosidade, dessa forma a identificação de características que indiquem espécies com folhas adaptadas ao sol ou à sombra tem relevante importância ecológica (Terashima et al., 2001). Ao avaliarem a taxa de crescimento de G. integrifolia e S. terebinthifolius sob sombra moderada e densa, Feijó et al. (2009) verificaram nas duas espécies uma diminuição significativa nas variáveis de crescimento sob baixa disponibilidade de radiação luminosa, demonstrando que as taxas de assimilação de carbono não foram suficientes para a produção de novos tecidos fotossintetizantes.

As folhas podem aumentar e diminuir a resistência à difusão de $\mathrm{CO}_{2}$ nos espaços intercelulares, diminuindo o tamanho das células (Terashima et al, 2001). Nos espaços intercelulares, a radiação é totalmente refletida, dessa forma espaços intercelulares mais amplos tornam possível a interface entre $o$ ar e água, que refratam e refletem a luz, resultando num maior aproveitamento do processo fotossintético (Santiago et al., 2001). Neste aspecto, notou-se uma resposta diferenciada entre as espécies, com a ampliação significativa dos espaços intercelulares para a espécie $G$. integrifolia nos tratamentos de 17, 10 e $5 \%$ de atenuação solar quando comparadas ao $25 \%$. No entanto para $S$. terebinthifolius não foi observada diferença significativa entre os tratamentos e o $25 \%$ do pleno sol (Figura 2B). Isto pode ter contribuído para o déficit na taxa fotossinteticamente ativa desta espécie quando submetido ao sombreamento denso como verificado por Feijó et al. (2009).

A variação da intensidade luminosa afetou consideravelmente a estrutura anatômica foliar de ambas as espécies, tanto a espessura total do mesofilo e do limbo foliar, acompanhado da redução das células dos tecidos fotossintético, demonstrando que as espécies possuem grande plasticidade fenotípica. Contudo, verificou-se que G. integrifolia foi a espécie que apresentou maior ajuste estrutural, quando comparada com S. terebinthifolius, Isto evidencia a capacidade de aclimatação a condições de sombra densa de $G$. integrifolia, indicando assim a potencialidade de cultivo desta espécie em ambiente agroflorestais, bem como em plantios mistos.

\section{CONCLUSÕES}

Os diferentes níveis de sombreamento ocasionaram alterações na estrutura do mesofilo de ambas as espécies, com diferenças significativas na espessura do parênquima paliçádico, limbo foliar e densidade estomática. Nas condições em que o experimento foi realizado os resultados obtidos indicaram que G. integrifolia apresenta maior capacidade de aclimatação a ambientes de sombra moderada e densa do que a $S$. terebinthifolius, sendo dessa forma, a mais indicada para o cultivo em sistemas agroflorestais pré-estabelecidos.

\section{AGRADECIMENTOS}

Essa pesquisa foi realizada com o apoio financeiro da Universidade Estadual de Santa Cruz (UESC) e da Fundação de Amparo a Pesquisa do Estado da Bahia (FAPESB). N.S.A. Feijó foi bolsista da FAPESB; Tiago Maldonado Secco foi bolsista de Iniciação Científica do CNPq; Marcelo S. Mielke e Fábio P. Gomes são bolsistas de Produtividade em Pesquisa do CNPq.

\section{REFERÊNCIA}

ARANDA, I. et al. Anatomical basis of the change in leaf mass per area and nitrogen investiment with relative irradiance within the canopy of eight temperate tree species. Acta Oecologica, v.25, p.187-195, 2004.

AKISUE, MK. et al. Caracterização farmacognóstica de pau d'alho Gallesia integrifólia (Spreng.) Harms. Revista Brasileira de Farmacognosia, São Paulo, v.1.n.2, p.166182, 1986.

BEERLING, D; MCELWAIN., J; OSBORNE, C. Stomatal responses of the 'living fossil' Ginkgo biloba L. to changes in atmospheric $\mathrm{CO}_{2}$ concentrations. Journal of Experimental Botany, v.49, n.326, p.1603-1607, 1998.

BRANT, RS. et al. Adaptações fisiológicas e anatômicas de Melissa officinalis L. (Lamiaceae) cultivadas sob malhas termorrefletoras em diferentes intensidades luminosas. Revista Brasileira de Plantas Medicinais, Botucatu, v.13, n.4, p.467-474, 2011.

CASTRO, EM. et al. Adaptações anatômicas de folhas

Rev. Bras. PI. Med., Campinas, v.16, n.1, p.89-96, 2014. 
de Mikania glomerata Sprengel (Asteraceae), em três regiões distintas da planta, em diferentes níveis de sombreamento. Revista Brasileira de Plantas Medicinais, v.9, n.2, p.8-16, 2007.

CASSANO, CR; SCHROTH, G; FARIA, D. Landscape and farm scale management to enhance biodiversity conservation in the cocoa producing region of southern Bahia, Brazil. Biodiversity Conservation, v.18, p.577603, 2009

CHAZDON, RL; FETCHER, N. Photosynthetic light environments in a lowland tropical rain forest in Costa Rica. Journal of Ecology, v.72, p.553-564, 1984.

CORDELL, S. et al. Physiological and morphological variation in Metrosideros polymorpha, a dominant Hawaiian tree species, along an altitudinal gradient: the role of phenotypic plasticity. Acta Oecologia, v.13, p.188-196, 1998.

DEMUNER, VG; HEBLING, SA; DAGUSTINHO, DM. Efeito do sombreamento no crescimento inicial de Gallesia integrifolia (Spreng.) Harms. Boletim do Museu de Biologia Mello Leitão, v.17, p.45-55, 2004.

DICKISON, WC. Integrative plant anatomy. Califórnia: Academic Press, 2000. 533p.

FEIJÓ, NAS. et al. Growth and photosynthetic responses of Gallesia integrifolia (Spreng.) Harms and Schinus terebinthifolius Raddi seedlings in dense shade. Agroforest Systems, v.77, p.49-58, 2008.

FELLER, IC. Effects of nutrient enrichment on leaf anatomy of dwarf Rhizohora mangle L. (Red Mangrove). Biotropica, v.28, n.1, p.13-22, 1996.

FREITAS, B. et al. Canigueral, S. Screening for antifungal activity of nineteen Latin American plants. Phytoterapy Research, v.12, p.427-430, 1998.

GOMES,IAC. et al. Alterações morfofisiológicas em folhas de Coffea arabica L.cv. "Oeiras" sob influência do sombreamento por Acacia mangium Will. Revista Ciência Rural, v.38, n.1, p.109-115, 2008.

GONDIM, ARO. et al. Plasticidade anatômica da folha de Taro cultivado sob diferentes condições se sombreamento. Bragantia, v.67, n.4, p.1037-1045, 2008.

GORTON, HL; WILLIANS, W. E; VOLGELMANN, TC. Choroplast movement in Alocasia macrorrhiza. Physiologia Plantarum, v.106, p.421-428, 1999.

GUERRA, MJM. et al. Actividad antimicrobiana de um extracto fluido al $80 \%$ de Schinus terebinthifolius Raddi (Copal). Revista Cubana de Plantas Medicinais, v.5, n.1, p. 23-25.2000.

HANBA, YT; KOGAMI, H; TERASHIMA, I. The effect of growth irradiance on leaf anatomy and photosynthesis in Acer species differing in light demand. Plant, Cell and Environment, v. 25, p.1021-1030. 2002.

JOHANSEN, DA. Plant Microtechnique. McGraw-Hill, New York, 1940. 523p.

KRAUS, JE; ARDUIN, M. Manual Básico de Métodos em Morfologia Vegetal. Edur. Rio de Janeiro. 1997. 198p.

LAMBERS, H; CHAPIN III, ST.; PONS, TJ. Plant Physiological Ecology. New York: Springer-Verlag, 2008. 540p.

LAVINSKY, AO. et al. Effects of light availability and soil flooding on growth and photosynthetic characteristics of Genipa americana L. seedlings. New Forests, v. 34, p.41-50. 2007.

LEAKEY, RRB.; SIMONS, AJ. The domestication and commercialization of indigenous trees in agroforestry for the alleviation of poverty. Agroforest Systems, v.38, p.165-176, 1998.

LIMA JR, EC. et al. Aspectos fisioanatômicos de plantas jovens de Cupania vernalis Camb. Submetidas a diferentes níveis de sombreamento. Revista Árvore, v.30, n.1, p.33-41, 2006.

LORENZI, H. Árvores Brasileiras: Manual de Identificação e Cultivo de Plantas Arbóreas Nativas do Brasil, 4ed. Instituto Plantarum de Estudos da Flora Ltda, Nova Odessa. 2002. 384p.

LORENZI, H; SOUZA, CV, Botânica Sistemática. Plantarum, 2005 p.639.

LUCENA, PLH. et al. Evaluation of the aroreira (Schinus terebinthifolius Raddi) in the healing process of surgical incision in the bladder of rats. Acta Cirurgica. Brasileira, v.21, n.2 p.46-50,2006.

MIYAJI, KI.; SILVA, WS.; ALVIM, PT. Productivity of leaves of a tropical tree, Theobroma cacao, grown under shading, in relation to leaf age and light conditions within the canopy. New Phytolologist, v.137, p.463-472, 1997.

MORAIS, H.et al. 2004. Modifi cations on leaf anatomy of Coffea arabica caused by shade of Pigeonpea (Cajanus cajan). Brazilian Archives of Biology and Technolog, v.47, p.863- 871, 2004.

NIINEMETS, U; SACK, L. Structural determinants of leaf lightharvesting capacity and photosynthetic potentials. In: ESSER K.; LÜTTGE UE.; BEYSCHLAG W.; MURATA J. Progress in Botany, Berlin: Springer Verlag,2006.p.385-419.

OGUCHI, R; HIKOSAKA, K; HIROSE, T. Does leaf photosynthetic light-acclimation need change in leaf anatomy? Plant Cell Environment, v. 26, p.505-512, 2003.

OGUCHI, R; HIKOSAKA, K; HIROSE, T. Leaf anatomy as a constraint for photosynthetic acclimation: differential responses in leaf anatomy to increasing growth irradiance among three deciduous trees. Plant Cell Environment, v.28, p.916-927, 2005.

OSUNKOYA, OO; ASH, JE; HOPKINS, MS. Influence of seed size and seedling ecological attributes on shade-tolerance of rain-forest tree species in northern Queensland. Journal of Ecology, v.82, p.149-163, 1994.

PAIVA, E. et al. The influence of light intensity on anatomical structure and pigment contents of Tradescantia pallida (Rose) Hunt. cv. purpurea Boom (Commelinaceae) leaves. Brazilian Archives Biology Technology v.46, p.617-624, 2003.

POORTER, L. Growth responses of 15 rain-forest tree species to a light gradient: the relative importance of morphological and physiological traits. Functional Ecology, v.13, p.396-410. 1999.

RAO, MR; PALADA, MC; BECKER, BN. Medicinal and aromatic plants in agroforestry systems. Agroforest Systems, v.61, p.107-122, 2004.

SAMBUICHI, RHR. Lista de árvores nativas do sul da Bahia. In: SAMBUICHI, RHR; MIELKE, MS; PEREIRA, CE. (Eds.) Nossas árvores: conservação, uso e manejo de árvores nativas do sul da Bahia. 1. Ed. Ilhéus: Editus, 2009. p.171-257.

SANCHES, MC. et al. Morfologia foliar de indivíduos jovens e adultos de Caesalpinia echinata Lam. numa floresta semidecídua do sul da Bahia. Revista Árvore,

Rev. Bras. PI. Med., Campinas, v.16, n.1, p.89-96, 2014. 
v.33, p. 885-893, 2009.

TERASHIMA, I; MIYAZAWA, S; HANBA, YT. Why are sun leaves thicker than shade leaves? Journal of Plant Research, v.114, p.93-105, 2001.

TICKTIN, T; SHACKLETON, C. Harvesting non-timber forest products sustainably: Opportunities and challenges. In: SHACKLETON, S.; SHACKLETON, C.; SHANLEY, P. (Ed.) Non-timber forest products in the global context. Heidleberg: Springer, 2011. p.149-170.

SANTIAGO, EJA. et al. Aspectos da anatomia foliar da pimenta longa (Piper hispidinervium C. DC.) sob diferentes condições de luminosidade. Ciências
Agrotécnicas, V. 25, p.1035-1042, 2001.

SCHROTH, G. et al. Conservation in tropical landscape mosaics: the case of the cacao landscape of southern Bahia, Brazil. Biodiversity and Conservation, v. 20, p.1635-1654, 2011.

VALLADARES, F; NIINEMETS, U. Shade tolerance, a key plant feature of complex nature and consequences. Annual Review of Ecology, Evolution and Systematics, v.39, p.237-257, 2008.

YANO, S; TERASHIMA, I. Developmental process of sun and shade leaves in Chenopodium album L. Plant, Cell and Environment, v.27, p. 781-793.2004. 